\title{
Discurso político y novelesco en la Gran Conquista de Ultramar
}

\section{Politic and Novelistic Discourse in the Gran Conquista de Ultramar}

\author{
Carmen Benito-Vessels \\ University of Maryland, College Park \\ cbenito@umd.edu
}

Los intertextos novelados de la Gran Conquista de Ultramar (GCU), entre los que destaca la Leyenda del caballero del cisne, son historias independientes, "estorias unadas", y su denominador común es la expresión de los objetivos políticos de Alfonso X, su patrocinador. Esta adopción narrativa (suma de historias) explicaría por qué la GCU ha recibido variados membretes genéricos. Benito-Vessels demuestra que la colección de "estorias unadas" de la GCU constituye un "ciclo" que podría tener otro título: Ciclo de estorias de la Gran Conquista de Ultramar.

En este ensayo se estudian los cuarenta y seis capítulos iniciales del primer libro y se hace particular énfasis en las "Estorias de Pedro el Ermitaño". La mayoría de las "estorias" incluidas en la GCU apunta hacia la defensa del "fecho del imperio". La GCU es una ficción estratégica dirigida a la realeza, en ella el discurso historiográfico pierde su independencia y la historiografía se ve, poco a poco, invadida por lo histórico imaginario.

Palabras Clave: "Estorias unadas", ciclos, ficción estratégica, "fecho del imperio", historia, novela y performance

The intertextual (hi)stories that make up the novel the Gran Conquista de Ultramar (CGU) among which shines the Leyenda del caballero del cisne - are, in fact, a compilation of independent histories: "estorias unadas". Throughout the stories, Alfonso X reveals his imperial political goals. This narrative technique (the sum of the "estorias unadas") explains why the GCU has been classified under so many different literary genres. Benito-Vessels shows that the GCU constitutes a cycle that could equally be titled: Ciclo de estorias de la Gran Conquista de Ultramar. This essay studies the first forty-six chapters of book one, focusing particularly on the "Estorias de Pedro el Ermitaño".

The GCU is a strategic fiction that directly addresses royalty in which the majority of the "stories" included point towards a defense of the "Alfonsine imperial project" (fecho del imperio). In the GCU, historical discourse loses its independence and the historiography is invaded by an imaginary historical discourse.

KeYWORDS: "Estorias unadas" or compilation of short (hi)stories, strategical fiction, imperial dream, History, novel and performance 
$\mathrm{L}$ a crítica siempre ha reconocido la importancia del discurso novelesco en La gran conquista de Ultramar (GCU); aunque los estudios sobre este tema se han centrado casi exclusivamente en la "Leyenda del Caballero del Cisne”. Sin embargo, la GCU ofrece la posibilidad de deslindar numerosos intertextos novelescos, o lo que es lo mismo, otras "estorias unadas" que en nada le van a la zaga a la mencionada "Leyenda del Caballero del Cisne". Para Alfonso $\mathrm{X}$ las "estorias unadas" son textos que van orientados al entretenimiento áulico; éste, a su vez, coexiste con el adoctrinamiento político y, como es natural, es el mejor cauce para dar expresión pública a la ideología particular de su patrocinador.

La apropiación del discurso novelesco en la GCU es tan significativa que la obra puede aceptar varios membretes genéricos para sí misma: "crónica caballeresca", "historia novelada", "gesta cristiana” y "compendio de leyendas históricas". Todo cabe en la GCU y, a riesgo de caer en una afirmación prematura, creo que esta obra se podría considerar como un ciclo: el Ciclo de estorias de la Gran Conquista de Ultramar. Con ello no haríamos sino secundar la denominación "Ciclo de las Cruzadas" con que normalmente nos referimos a La Chanson d'Antioche, Les Chètifs, La Conquête de Jèrusalem, la Chanson du Chevalier au Cygne y Enfances de Godefroid de Bouillon.

En este artículo intentaré analizar cómo se combinan el discurso de la ficción en el que se sustenta el relato historiográfico de la GCU y los postulados teóricos de la escritura en los que se basa el discurso de autoridad política. ${ }^{1}$ La GCU, lo mismo que todas las crónicas y textos de carácter histórico de la Edad Media, gozó y goza de estatus oficial. Por consiguiente, en esta obra y en toda la historiografía medieval se institucionaliza el vasto componente fictivo que allí se incorpora. La pretendida ejemplaridad de los textos historiográficos es, sin lugar a dudas, uno de los mejores instrumentos de propaganda política y el éxito de los mismos dependía en gran medida de su aceptación oficial.

Se mire como se mire, la historia es salvaguarda del pasado verdadero y del mítico, y es también el resultado de una acción verbal. Como dice Georges Martin (Les juges): la historia es discurso. En mi opinión, los conceptos de "dominación" y "conquista" que se defienden en la GCU son resultados de formaciones discursivas cuya construcción se basa en la escritura y los múltiples significados de la misma.

\footnotetext{
${ }^{1}$ En cuanto al modo mismo de composición conviene recordar dos características de la historiografía medieval: el hombre medieval considera que "todas las fuentes sobre un suceso conservan alguna parte de verdad" y para el historiador "la correcta transmisión de la historia no está reñida con la (re)elaboración personal de los contenidos enteros [...] por eso los historiadores pueden inventar desde anécdotas hasta episodios enteros" (Fernández Ordóñez, "La historiografía", 102).
} 
Como muestra de la interacción política y novelesca en la GCU voy a considerar el prólogo y los cuarenta y seis capítulos iniciales del primer libro; dichos capítulos, en la edición de Cooper, preceden inmediatamente a la "Leyenda del Caballero del Cisne" y constituyen una unidad narrativa que, de principio a fin, ofrece un desarrollo episódicamente novelado y textualmente delimitable. Es decir, estos capítulos constituyen una de las que yo considero estorias unadas de la GCU. En mi opinión, la "Leyenda del Caballero del Cisne”, las estorias de Tranquer, la de Berta, hija de Flores y Blancaflor, la de la reina Halabra y la del propio Godofredo de Bouillon serían otras de las "estorias unadas"; todas ellas, consideradas en su conjunto, constituirían el Ciclo de estorias de la Gran Conquista de Ultramar al que aludí anteriormente.

Siguiendo este criterio, en adelante me referiré al corpus elegido con el título provisional de la "Estoria de Pedro el Ermitaño". El móvil de esta estoria, lo mismo que el de la GCU, es la recuperación de Jerusalén; en ella se combinan lo profano y lo sacro dentro de un ambiente caballeresco que refleja fielmente la totalidad de la obra. El linaje que reivindican los protagonistas de la "Estoria de Pedro el Ermitaño” es el de la cristiandad y éste se presenta como superior a cualquier otro de los del orbe. Al igual que en las novelas de caballerías, el linaje en la "Estoria de Pedro el Ermitaño" obliga a la recuperación territorial (GCU I, 26); en nombre de la cristiandad se rescatan territorios de manos paganas y se hacen estratégicas donaciones a Dios: "E quando [Godofredo] quiso mover para yr complir su romería a Ultramar, dio aquel castillo en limosna a nuestro Señor Dios; e porque era la más alta heredad e la mejor que el avía, diola a la mayor yglesia jamás" (GCU I, 321). Los peligros de las aventuras caballerescas de Pedro el Ermitaño se sufren en pro de la colectividad cristiana, pero sus éxitos redundan en beneficio personal y de linajes individuales:

E comoquier que todas estas cosas desmayassen al pueblo de los cristianos, todavía los hombres buenos que ay estavan los esforçavan mucho [... ] diziéndoles que no podrían ellos sofrir cosa, en servicio de Jesucristo, que fuese nada en comparación de lo que él sufriera por ello demás que aquel era lugar para estremarse los buenos de los malos, ca el que muriesse yría derechamente al parayso, e aquel que ende escapasse, fincaría por bueno e habría siempre buena fama, e quantos dél viniessen; e los que allí muriessen, siendo malos e covardes, yrían al infiemo, e los que escapassen, quedarían amenguados e reputados por viles, e no osarían parescer entre los hombres, serían denostados todos los que dellos descendiessen (GCU I: 449).

Nada concierne tanto a Alfonso X como la expansión de su línea genealógica. Por la teoría de "la linna" Alfonso X es sucesor de Nemrod, que a su vez es 
sucesor de Cam, que reinó en África y que además se identifica con Saturno. Alfonso logró semiemparentarse con Godofredo de Bullón (González, La tercera crónica), pero lo que a mí me parece fundamental es que la superioridad de éste procede directamente del linaje de la cristiandad reivindicado en la "Estoria de Pedro el Ermitaño". Por tal razón resulta inexcusable que Alfonso X, aduciendo bancarrota, no colaborase en la cruzada dirigida por Urbano IV para recuperar Constantinopla. Por todo ello, la defensa de la campaña papal en la GCU vendría a subsanar este error político - si aceptamos que el texto fue planeado como un intento de exculpación, una suerte de acto penitencial y, sobre todo, un intento político de participación vicaria en dicha cruzada - Este tanto a favor del papado no podía sino beneficiar a aquel rey cuyo gran fracaso en el "fecho del Imperio" se debía a que no uno, sino cuatro papas, Urbano IV, Clemente IV, Alejandro IVy Gregorio $\mathrm{X}$, se negaron sucesiva y rotundamente a reconocerla nominación imperial que se efectuó en agosto de 1257 (O'Callaghan, The Learned King, 198-214).

La escritura de la historia con fines políticos fue práctica común en el taller alfonsí. Hace ya años, Charles Fraker ("Alfonso X") llamó la atención sobre la conexión entre la Estoria de España y el Imperio; más recientemente Cristina González (La tercera crónica) ha argumentado con extraordinario éxito cómo la compilación y propósito de la GCU debió ser un último intento alfonsí para reforzar sus alianzas con Francia e Inglaterra y para recuperar Jerusalén. Por otra parte, es sabido que la autoridad política y la autoridad de escritura están siempre presentes en la obra alfonsí y muy en particular en su obra tardía; es decir, en la obra planeada en los momentos de mayor debilidad gubernamental. ${ }^{2}$ En la GCU la autoridad política de Alfonso X se afirma desde el prólogo, allí el rey dice que manda trasladar "la ystoria de todo el fecho de Ultramar para que los hombres sigan los buenos fechos de los buenos hombres en su servicio a Dios" (GCU, 2). El Rey Sabio propone la institucionalización de un orden moral y político y, en este sentido, la GCU es un discurso de poder en el que la realeza es a la vez instigadora y destinataria del texto. El orden regio y la justicia se vinculan indisolublemente a la divinidad en esta crónica. Tanto en el citado prólogo como en el colofón a la "Estoria de Pedro el Ermitaño" hay buena prueba de ello; al final de la misma leemos:

Desta guisa que vos diximos fue desbaratada aquella compaña de los pelegrinos que yvan a Ultramar. E todo hombre deve entender que esto acaesció porque

${ }^{2}$ El Setenario es la obra que para Georges Martin representa expresión última y más acabada del ideal político de Alfonso X; aunque también sea la más marcada por un contexto caótico (“Alphonse X”, 85-86). 
yvan en servicio de Dios, no seyendo sus amigos, como dixo el profeta y rey David: que no entraría en la casa de Dios sino aquel que fuese sin manzilla e fiziesse justicia. Ca aquellos eran de malas costumbres e de mala vida a demás, yvan faziendo por aquel camino muchas sobervias e muchas fuerças que eran contra justicia, e por esso fueron vencidos, como ya oystes (GCU I, 80; subrayado mío).

En esta misma estoria hay una clara división de los episodios que se usan para ejemplificar el bien y el mal, o, mejor dicho: el buen y el mal liderazgo, ya que la autoridad moral y la autoridad política van unidas. En los cuarenta y seis primeros capítulos, los malos por antonomasia son los moros o turcos; de entre los cristianos, los alemanes, a quienes se describe como los peores alteradores del orden, son los más innobles de la expedición (GCU I, 57-75), los húngaros, por otra parte, son representados como individuos brutos y perversos. Por tanto, ni turcos ni húngaros ni alemanes ofrecen un buen liderazgo en estos pasajes:

tan presto como los ungreses ovieron las armas en su poder, començáronlos a matar e a despedaçar todos [a los peregrinos], sin saber quáles ovieron culpa en los malos fechos o quáles no, e tantos mataron dellos, que bien fasta las rodillas andavan por la sangre; assí que gran duelo e gran piadad avría todo hombre que viesse yazer muerta tanta fermosa compaña por los caminos e por los campos (GCU I, 77).

La maldad de moros y cristianos en la GCU es de distinta índole; la del moro se presenta como intrínseca y gnoseológica: "todas las cosas en que Mahoma loava en su Alcorán a nuestro Señor Jesucristo e a Santa María, ellos entendían al revés, e las interpretavan a la peor parte” (GCU I, 15). Según dice el texto, los moros eran, literalmente, "mala gente" (GCU I, 46) mientras que la maldad del cristiano en el texto es accidental y causada por agentes externos; así se justifica en la GCU que los turcos tomaran Jerusalén:

en aquel tiempo pocos eran aquellos [cristianos] que hombre fallasse que amasse ni temiessen a Dios, ni que oviessen miedo ni vergüença de mal hazer. E havian dexado toda carrera de derecho e lealtad, e piedad e misericordia, e de justicia [... ] Mas tanto estavan metidos en vileza e mal, e ansí estavan embueltos en ellos, que aunque veyan todos estas señales que Nuestro Señor diera, no avían miedo ni oyan ni entendían ninguna cosa de bien; antes los avía el diablo afogados (GCU I, 27). 
Más adelante se dice que "el diablo que nunca está en paz, e se trabaja quanto puede en estorvar los fechos de Dios, con esta paz que los cristianos avían entre sí pesávale dello mucho” (GCU I, 57). De todos los personajes de la "Estoria de Pedro el Ermitaño" el más execrable es el dueño del castillo de Amabilia, el rey Catamán de Hungría, a quien se imputa repetidamente la crueldad de sus súbditos. De entre los buenos hay varios líderes que colaboran con Pedro el Ermitaño, destacan sobre todos Gualter Sinsaber y el propio emperador de Constantinopla, quien recibe a Pedro el Ermitaño en el alcázar de Bocaleón, La ambientación y planteamiento de los hechos deja ver que la "Estoria de Pedro el Ermitaño" no pretende expresar los acontecimientos al modo de las "estorias departidas" por años, sino que se presenta como un relato novelado para justificar que los moros son malos y no merecen poseer los

164 Santos Lugares, en tanto que los cristianos son valerosas víctimas de aquellos. Los cristianos han sido despojados de su heredad, pero su "buen linaje" los obliga a recuperarla. Dentro del grupo de los cristianos, empero, los alemanes no merecen el liderazgo ni en la GCU ni, mucho menos, en opinión de Alfonso $\mathrm{X}$, fuera de ella.

En la "Estoria de Pedro el Ermitaño" hay prohibiciones que, como en las novelas de caballerías, los héroes transgreden para crecer en su virtud (GCU I, 63-66). Se veta que los cristianos crucen el brazo de san Jorge y ataquen a los húngaros; sin embargo, aquellos hacen caso omiso de las restricciones para mostrar que no temen la muerte en nombre de Dios. Otro tipo de transgresiones ejemplifica la debilidad de espíritu de algunos cristianos como la de aquellos que compelidos por el hambre se pasan al enemigo:

los cristianos avía bien dos días que no comieran e que estaban muertos de fambre [...] y [los moros] asentáronse luego a comer ante ellos, e conbidáronlos si querían comer pan e vino e carne, e de lo que sabor avían de comer; mas los hombres honrados quisieron antes ser muertos o presos, E mostrávanles la carne, el pan e lo que ellos comían; e algunos de la gente menuda se fueron a eilos, a ser sus cativos (GCU I, 70).

La sucesión de prohibiciones y transgresiones, al igual que los nombres y ambientación de los episodios, contribuye a reforzar el discurso novelesco: en la "Estoria de Pedro el Ermitaño" hay luchas sanguinolentas y rebeldes sublevaciones en pro de la contienda; así, por ejemplo, se nombra al conde Hermicon como líder de las huestes que habían atacado a los judíos de Colonia e iban sin caudillo a Ultramar (GCU I, 78-79). Además, en el texto se recurre a la intervención divina cuando es necesario favorecer a los buenos $y$, 
finalmente, la acción se desarrolla en lugares remotos cuya ubicación permite la fabulación sobre los mismos. Remotísimos debían ser para el castellano de a pie de los siglos XIII y XIV los lugares de procedencia de los peregrinos en la "Estoria de Pedro el Ermitaño": Hungría, Dinamarca la Menor y Alemania. Sin embargo, no por ello se deja de percibir la historicidad documental de las hazañas ya que los personajes citados, el telón de fondo y la cronología son datos empíricamente comprobables. La GCU es un magnífico exponente de cómo al aproximarse a la realeza, el discurso historiográfico pierde su independencia y la historiografía se ve poco a poco invadida por lo histórico imaginario, lo cual dará paso a la privatización del discurso histórico en los siglos XIV y XV (Martin, Les juges, 211).

La manifiesta animosidad alfonsí contra los germanos y otros pueblos centroeuropeos está presente en la GCU y bien pudiera leerse como un modo de subrayar la "necesidad" que estos pueblos tenían de un buen líder; un líder que, como Alfonso el Sabio, estuviese en buenos términos con la divinidad ya que sólo a través de la protección regia habría protección divina. En los pasajes seleccionados de la GCU se dice claramente que Dios sostiene en los altos estados a los buenos reyes cristianos y a los hombres honrados y que si Dios ayuda a su pueblo es "más por amor de ellos [los reyes y hombres honrados] que no por nuestros merescimientos" (GCU I, 35).

Sabemos que Alfonso X debió planear la GCU hacia el final de su reinado y, lo mismo que la Estoria de Espanna, se habría compilado en tiempos del Rey Sabio pero conocido su redacción final en tiempos de Sancho IV. Lamentablemente a partir de 1282 Alfonso no tenía nada más que un reino que se había vuelto contra sí y a favor de su hijo heredero. Con todo, el pensamiento político alfonsí sigue vigente en tiempos de Sancho IV:

Mais non; le Septenaire n’a pas éíé composé par Alphonse a la demande de son pare dans les années précédant et suivant immédiatement la mort de celui-ci [...]. Cette légende fait aussi partie de "miroir" que parmi l'inventaire de son héritage, Alphonse legue par testament a son sucesseur afín que lui-méme et les rois qui vlendront aprés lui [...] sachent amender leurs fautes et celles des autres et redresser leurs faits (Martin, "Alphonse X", 100).

Alfonso se resiste a admitir la deprimente realidad histórica que le toca vivir e intenta oponerse a las circunstancias adversas a través de la escritura. De la GCU puede decirse lo mismo que Georges Martin dijo del Setenario: es una gran ficción estratégica. Por lo demás, de todo texto historiográfico se puede afirmar que: "La façon dont se constituent les textes narratifs dépend 
de rutilisation qu'on veut en faire, et done de leur situation dans le contexte verbal ou extra-linguistique qui les ensene (Stierle, "L'histoire”, 178)."

A mi modo de ver, toda la obra historiográfica alfonsí, y muy en particular la GCU, constituye un proyecto textual a través del cual es posible vivir vicariamente el sueño imperial de su promotor. Lejos de ahondar en el fracaso, Alfonso enfatiza el triunfo que supuso su nominación y crea su imperio con base en textos: el suyo fue un imperio en pergamino y como tal es menester tratarlo. No es una nimiedad el que Alfonso estableciera una analogía entre su nombre y los de Dios; ${ }^{3}$ el Rey Sabio sigue la identificación entre palabra y referente y su conexión con la divinidad -éstas son ideas de los gramáticos cristianos como Anastasio (m. $373 \mathrm{AD}$ ) quien, en De incarnatione verbi, afirmó que: la historia de la humanidad era la actualización de la palabra de Dios 166 (Amsler, Etymology, 92) —. La autoridad política y literaria del Rey Alfonso está omnipresente en su obra y la autojustificación para reivindicarla no tiene límites; Alfonso dice de sí mismo en el Espéculo (1, I, 13) que nadie le superaba en "autoridad en lo temporal". Semejante arrogancia se queda corta frente a la mencionada argumentación lingüística en la que Alfonso establece una correspondencia directa entre su propio nombre y los siete nombres de Dios. Más aún, con las siete letras que por designio divino componen el nombre de Alfonso, afirma el Rey Sabio, Dios le envió los siete dones del Espíritu Santo. La onomástica y la autoridad de la palabra son vitales en ciertos pasajes de la "Estoria de Pedro el Ermitaño"; recordemos, por ejemplo, los nombres de Catamán, Amabilia y Bocaleón aquí mencionados y cómo corresponden a un mal líder, a un castillo que no debía pertenecer a dicho líder por su mal gobierno y a un lugar regio donde Pedro el Ermitaño defiende a los suyos frente al emperador de Constantinopla. Recordemos asimismo la mención a cómo los moros lo entienden todo al revés y por eso son descreídos de Dios, o cómo el emperador de Constantinopla queda obnubilado frente a la locuacidad del Ermitaño.

Alfonso X está bien a la par de las teorías gramaticales de la Antigüedad y de su propia época. Según Hans Niederehe (Alfonso el Sabio) el Rey

\footnotetext{
${ }^{3}$ La interpretación de nombres bíblicos es la práctica más documentada y más conocida de la gramática medieval y, como sabemos, no es ajena a la cábala judía. Mark Amsler afirma que "as an interpretíve strategy, it is deployed in various discourses: Christian poetry, historiography, scriptural exegesis, homilies, apologetics, and so on. Between the second and fifth centuries A.D. sacred onomastics presented the principal challenge to the authority of secular technical grammar and also constituted the Christian appropriation of Hellenistic exegetical grammar" (Etymology, 82-83).
} 
Sabio llegó incluso a participar en las disputas científicas de Francia y de los utilitaristas de Italia. La reforma de la ley de Fernando III y de Alfonso X seguía el modelo italiano donde Derecho y Lingüística iban unidos. ${ }^{4}$ Alfonso da repetidas pruebas de que para él hay —y permítaseme el anacronismouna conexión semántica basándose en similaridades fonéticas y, según creo, establece también una conexión semántica basándose en similaridades circunstanciales o, si se prefiere, en la lectura anagógica de la historia. ${ }^{5}$ Por todo ello me parece crucial el demérito achacado a los alemanes en la "Estoria de Pedro el Ermitaño”, máxime cuando esta narración se sitúa estratégicamente al comienzo de la obra, junto con la disculpa alfonsí por no haber participado en la cruzada y por no haber ido al concilio convocado por Urbano IV ni haber sido cruzado:

Otros muchos honrados hombres fueron allí, de los quales no son aquí scriptos sus nombres; e sin éstos, fueron ay muchos arzobispos e obispos e abades benditos, e otros hombres de orden, tantos, que apenas cabrían en un gran escripto. El rey don Alfonso de España quisiera yr con ellos, sino porque tenía cercada la cibdad de Toledo (GCU I, 49).

En conclusión, opino que es indispensable considerar esta monumental obra como documento sobre el que se pretendía institucionalizar la autoridad y el derecho al Imperio. El espacio que se quiere conquistar goza de las prerrogativas del espacio mítico y del real y para hacerse acreedor a los derechos a poseerlo, Alfonso X recurre a la genealogía y a la escritura novelada de una Historia que se puede dar como propia.

En mi opinión, el término "novelesco" aplicado a la GCU no tiene función adjetiva monosémica; cuando nos referimos a la GCU como texto "histórico-novelesco" estamos aceptando una bisemia en la que lo considerado novelesco participa de lo factual y de lo ficticio. De este modo, resulta que el relato supuestamente factual no es más que un relato que

\footnotetext{
${ }^{4}$ El propio Toledano había estudiado en Bolonia. En Alfonso X falta el aspecto literario característico de la escuela de Orleans. Los autores son testimonio - aún por descifrar- de la historia de la salvación. Importa, por tanto su valoración literaria más que la lingüística propiamente dicha (Niederehe, Alfonso el Sabio, 11-38).

${ }^{5}$ Las conexiones semánticas llevan con frecuencia a establecer falsas etimologías y evoluciones semánticas erróneas. Esto se debe al "afán de explicar cada elemento definido desde su origen mismo, — para descubrir en él la esencia de las cosas—, como si cada una de ellas fuera una partícula que contribuye a la armonía cósmica, aunque tal etimología sea errada" (Rubio Moreno, Leyes, 781).
}

Medievalia 50, 2018, pp. 159-169 
nos permite aceptar la ficción como parte necesaria del discurso histórico medieval. Es decir, la categoría de un género (historia) y sus enunciados (documentales) inducen a una representación (en el sentido de iteración) que aceptamos como discurso factual; mientras que la otra categoría (novela caballeresca) y los enunciados de que se sirve (indemonstrables) inducen a una representación (en el sentido de performance) que es parcial, subjetiva y política. Iteración y performance son, en realidad, principios básicos del pensamiento historiográfico medieval y permiten la inclusión de historias universales o bíblicas dentro de historias y crónicas castellanas. Lo sofisticado en el caso de la GCU es, justamente, la apropiación alfonsí de los triunfos particulares que ocurren en Ultramar. ${ }^{6}$ El conjunto de las "estorias unadas" que integran la GCU constituye un collage narrativo o, como yo preferiría llamarlo, un ciclo de estorias que, a juzgar por el número de manuscritos conservados, gozó de gran popularidad y, en este sentido, se integra plenamente en el proyecto histórico/político de fines del XIII y principios del XIV. ${ }^{7}$

\section{BiBLIOGRAFÍA}

Amsler, MARK, Etymology and Grammatical Discourse in Late Antiquity and the Early Middle Ages, Amsterdam: John Benjamins, 1989.

Benito-Vessels, Carmen, "Heterotopía e Imperio soñado en la Gran conquista de Ultramar", Revista de Poética Medieval, en prensa.

Cooper, Luis, (ed.), Gran conquista de Ultramar, 4 vols., Bogotá: Instituto Caro y Cuervo, 1979.

Fernández Ordóñez, Inés, "La historiografía alfonsí y post-alfonsí en sus textos. Nuevo panorama”, Cahiers de Linguistique Hispanique Médiévale, 18-19: 4, 1993-1994, 102-132.

Fraker, Charles, "Alfonso X, the Empire and the Primera crónica", Bulletin of Hispanic Studies, 55, 1978, 96-102.

GonZÁlez, CRISTINA, La tercera crónica de Alfonso X: "La gran conquista de Ultramar", Londres: Tamesis, 1992.

\footnotetext{
${ }^{6}$ Para este tema véase mi "Heterotopía e Imperio soñado en la Gran conquista de Ultramar" de próxima publicación en la Revista de Poética Medieval de la Universidad de Alcalá de Henares.

${ }^{7}$ La pluralidad de fuentes usadas en la $C G U$ favorece esta fragmentación y hace años George T. Northup ("La Gran conquista") dio buena cuenta de ello.
} 
Martin, Georges, “Alphonse X ou la science politique”, Cahiers de Linguistique Hispanique Médiévale, 18-19, 1993-1994, 79-100.

Martin, Georges, Les juges de Castille. Mentalités et discours historique dans l'Espagne médiévale, Paris: Annexes des Cahiers de Linguistique Hispanique Médiévale, 6, 1992.

Niederehe, Hans J., Alfonso el Sabio y la lingüística de su tiempo, tr. Carlos Melches, Madrid: Sociedad General Española de Librerías, 1987.

Northup, George T., "La Gran conquista de Ultramar and its Problems", Hispanic Review, 2: 4, 1934, 287-302.

O'Callaghan, Joseph F., The Learned King: The Reign of Alfonso X of Castile, Philadelphia: University of Pennsylvania Press, 1993.

Rubio Moreno, Laura, Leyes de Alfonso X, vol. III. Contribución al estudio de las definiciones léxicas de "Las Partidas" de Alfonso X El Sabio, Ávila: Fundación Sánchez Albornoz, 1991.

Stierle, Karlheinz, "L'histoire comme exemple, l'exemple comme histoire: contributtion a la pragmatique et a la poétique des textes narratifs", Poétique, 10, 1972, 176-198. 
